\title{
A Very Rare Complication After Appendectomy in a Young Adult Patient: Abscess of the Greater Omentum
}

\author{
Yuri N. Shiryajeve, b, c, Anna V. Glebovaa, , Maria A. Bernstein ${ }^{\mathrm{a}, \mathrm{b}}$, Nikolay Y. Kokhanenko ${ }^{\mathrm{a}}$
}

\begin{abstract}
An 18-year-old male patient was operated on for perforated appendicitis. An appendectomy combined with an omental resection was performed. On the 6th postoperative day, chickenpox was diagnosed, and the patient was transferred to an infectious diseases hospital. On the 16th postoperative day, the patient was readmitted with pain in the area of the postoperative scar, and body temperature of $38^{\circ} \mathrm{C}$. Substantial tenderness in the right iliac fossa without rigidity and peritoneal irritation was found on examination. By ultrasonography, a non-homogeneous hypoechoic mass measuring $40 \times 37 \mathrm{~mm}$ without clear borders in the right iliac fossa was visualized, with a small amount of free fluid. The patient was reoperated on. An abscess of the greater omentum was found, and resection of an omental mass with the abscess cavity was performed. The postoperative course was uneventful, and the patient was discharged on the 15 th day. We discuss previously published data on postoperative omentitis and omental abscess. Our case is a very rare case of an omental abscess that developed after appendectomy in a young adult patient.
\end{abstract}

Keywords: Appendicitis; Appendectomy; Complications; Omental abscess

\section{Introduction}

Intraabdominal abscesses after appendectomy are serious

\footnotetext{
Manuscript accepted for publication December 11, 2013

${ }^{a}$ Department of Faculty Surgery named after Professor A.A. Rusanov, Saint-Petersburg State Pediatric Medical University, Saint-Petersburg, Russian Federation

${ }^{\mathrm{b}}$ Sixth Department of Surgery, Mariinsky Hospital, Saint-Petersburg, Russian Federation

${ }^{\mathrm{c}}$ Corresponding author: Yuri N. Shiryajev, Department of Faculty Surgery named after Professor A.A. Rusanov, Saint-Petersburg State Pediatric Medical University, Litovskaya str., 2, 194100

Saint-Petersburg, Russian Federation. Email: shiryajev@yandex.ru
}

doi: http://dx.doi.org/10.4021/jmc1654e complications requiring surgical intervention. Moreover, they can cause subsequent complications and even fatal outcomes. Their locations vary: pelvic, subdiaphragmatic, interintestinal, subhepatic, retrocecal, intramesenteric, and so on [1-3]. One of the rarest kinds of intraabdominal abscess is an abscess of the greater omentum [4]. We present a very rare case of this complication that developed in a young adult patient after appendectomy for perforated appendicitis.

\section{Case Report}

An 18-year-old male was urgently admitted on August 6, 2009 with typical symptoms of acute appendicitis $40 \mathrm{~h}$ after onset of the complaints. A blood test showed leucocytosis of $22.6 \times 10^{9} / \mathrm{L}$. The patient was operated on via McBurney's approach. A large amount of purulent fluid was evacuated from the right iliac fossa and pelvis. The vermiform appendix was surrounded by part of the greater omentum. The former was gangrenous with a perforation 3 - $4 \mathrm{~mm}$ in diameter close to the cecal wall. The attached omentum was severely inflamed with hyperemia, edema, red-purple coloration (in parts) and fibrin adhesions. A typical appendectomy with an omental resection was performed. The inflamed area of the omentum was excised and ligated using caprone sutures $3 / 0$. The pelvic cavity was drained and the wound was sutured.

Antibacterial treatment was administered (ceftriaxone $1 \mathrm{~g}$ twice daily intramuscularly, metronidazol $500 \mathrm{mg}$ twice daily intravenously). Body temperature remained high (maximally $39^{\circ} \mathrm{C}$ ) for the first 3 days. On the 4 th day postoperatively, a maculopapular rash appeared. A dermatologist suggested that the patient had acute allergic dermatitis as a complication of antibacterial therapy. Prednisolone and antihistamine drugs were added to the treatment regime. However, there was no improvement, and on the following day, against a background of the existing papulae and spots, small vesicles appeared. At that time, the pelvic drain was removed, and wound or intraabdominal complications were excluded. We suspected a diagnosis of chickenpox that was confirmed by the dermatologist. The patient was transferred to the infectious diseases hospital, where he was treated for the next 8 days and then discharged with clear improvement 


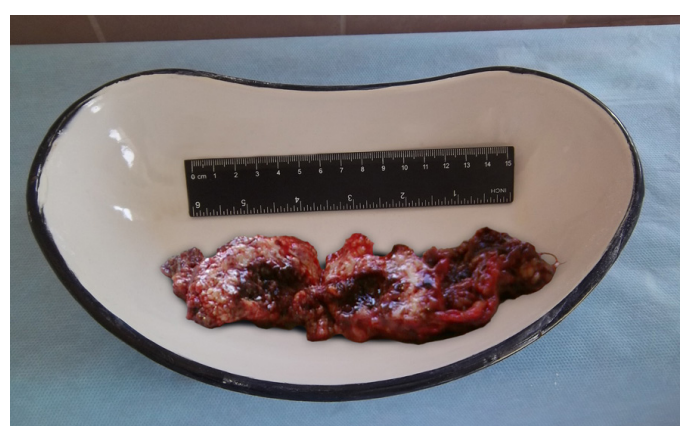

Figure 1. The resected specimen: a part of the greater omentum with the abscess cavity in the middle. A caprone ligature (not shown) was removed from the abscess.

and natural evolution of the rash elements.

However, the patient started to complain of a dull pain in the area of the postoperative scar, accompanied by an increase in body temperature to $38^{\circ} \mathrm{C}$. He was readmitted on the 16th day after surgical intervention, with a suspected intraabdominal abscess. Examination revealed substantial tenderness in the right iliac fossa without rigidity or signs of peritoneal irritation. Examination per rectum revealed no abnormalities. A blood test showed the following: leucocytosis $17.6 \times 10^{9} / \mathrm{L}$, erythrocytes $4.7 \times 10^{12} / \mathrm{L}$ and hemoglobin $129 \mathrm{~g} / \mathrm{L}$.

An ultrasound (US) examination revealed a non-homogeneous hypoechoic mass in the right iliac fossa, measuring $40 \times 37 \mathrm{~mm}$ without clear borders, plus a small amount of free fluid. Based on the typical clinical data and US findings, we stopped the examination process, avoiding computed tomography $(\mathrm{CT})$ or magnetic resonance imaging. Indications for surgery were established, and the patient consented to the procedure.

The abdomen was opened via the old scar. There were no purulent collections in area of the approach. The cecum and appendectomy area appeared normal. We were able to palpate a firm mass surrounded by the greater omentum or formed by the omentum in the right colic gutter. The wound was extended in the cephalad direction. During the separation of the omental mass from the lateral abdominal wall, the abscess was drained and $10-15 \mathrm{~mL}$ of pus was discharged. Finally, the mass was mobilized, and the omentum forming this mass was resected. The specimen removed was part of the greater omentum, and measured $12 \times 8 \mathrm{~cm}$ with an abscess cavity of ovoid form measuring $4 \times 3 \mathrm{~cm}$ (Fig. 1). A caprone ligature was removed from the abscess cavity. After specimen removal, a cavity measuring about $5 \times 5 \mathrm{~cm}$ appeared in the retroperitoneal fat, with mild capillary bleeding. This was packed with two gauze tampons and a rubber tube. The wound was closed up to the tampons. Bacteriologic tests showed the growth of Escherichia coli sensitive to most antibiotics. The postoperative course was uneventful. The tampons were replaced under narcosis on the 6th day, and were completely removed on the 15 th day. The patient was discharged in a satisfactory condition on the 15 th postoperative day.

On follow-up 4 years later, the patient had no complaints and was in a good condition. He now has a small aponeurotic defect in area of the scar without the clinical appearance of hernia.

\section{Discussion}

An omental abscess is a very rare complication after appendectomy. In certain monographs on postappendectomy complications and intraabdominal abscesses, this condition is not even mentioned [1-3]. However, some papers on this topic have been presented in the literature. Most of them were published in the 1970s and 1980s, and almost all in Soviet periodicals (see References).

An omental abscess can be considered as a particular type of omentitis. Primary omentitis develops without prior surgery as a result of torsion, ischemia, thromboembolic lesions, or hematogenous or lymphogenous transfer of infection. Secondary omentitis is usually a complication of an inflammatory process in another abdominal organ, but can develop after contamination of the omentum during surgery (for example, its resection) and after invasion by foreign bodies from the hollow digestive organs [5]. Omentitis can be classified according to clinical course (acute and subacute), and degree of inflammation (catarrhal, phlegmonous, phlegmonous-necrotic, phlegmonous-abscessed). Secondary omentitis is diagnosed much more frequently than primary omentitis [5-8], and non-abscessed forms more often than omental abscess $[5,6,9]$. Purulent omentitis after appendectomy can be considered a very rare complication. Cortesi et al [4] described only one case in a group of patients operated on for acute appendicitis $(\mathrm{n}=8738)$, with an incidence of $0.011 \%$. Bairov and Golovanov analyzed 18 years of data from pediatric hospitals of two Soviet cities, Leningrad and Arkhangelsk (47,859 operations for acute appendicitis), and found only 10 cases of omental abscess $(0.02 \%)$ [9].

Interestingly, omentitis in general and omental abscess in particular - as a complication after appendectomy - are much more common in the pediatric population than in adults, and this has been emphasized in many relevant publications $[5$, 7, 9-15]. Adult cases of omental abscess after appendectomy are extremely rare. Two cases were presented by Druianov et al [16], and one case by Cortesi et al [4]. Paliuga described a patient that was operated on for intraabdominal abscesses in different locations three times after appendectomy; one of the abscesses was located in the greater omentum [17]. In some papers on acute and chronic omentitis, there was no clear description of prior surgical interventions $[6,8]$. Thus, in material from Soviet authors, there were six patients with an abscess in the middle of an inflamed omentum, and all 
had received prior surgery [6].

Purulent omentitis after appendectomy is almost always recorded in patients operated on for destructive (usually gangrenous) appendicitis complicated by peritonitis $[5,9,12$, 13]. In most cases, primary appendectomy was combined with an omental resection for secondary inflammatory involvement of the greater omentum $[7,10,12]$.

Clinical symptoms of the omental abscess are local abdominal pain, febrile fever and signs of systemic inflammation. Palpation shows local tenderness and often a mass [5, $9,12,15]$. These features are not present immediately after appendectomy, but are usually delayed by 7 - 8 days [15] to 25 - 30 days [12]. Until that time, in most cases the patient's condition becomes satisfactory, body temperature is normal, and inflammatory changes recorded via blood test improve [12]. After this "lucid interval", some patients are discharged, and are only readmitted following the appearance of the abovementioned symptoms. Previously published data show that a relapse of indolent inflammation in the omentum can be provoked by viral infection [12], as in our patient.

There are few data on the efficacy of different instrumental methods in the diagnosis of purulent omentitis. We believe it is caused by the fact that most relevant papers were published before the introduction of the most valuable visualization tools (US examination, CT, magnetic resonance imaging) into widespread clinical practice. Some authors noted the insufficient efficacy of US [7, 12], except in cases in which the inflammatory focus in the omentum is located near the abdominal wall. In contrast, Bairov and Golovanov [9] considered US as a valuable tool in the diagnosis of omentitis. Iudin et al used electromyography for topical and differential diagnosis of secondary omentitis in 5 of 17 cases [15] and recommended this method. However, their recommendation is now out of date due to the high level of development of direct visualization techniques (US, CT, magnetic resonance imaging). In our case, the diagnosis was confirmed by US only, but in difficult cases CT can improve the diagnostic accuracy [18], as in other omental lesions, for example, partial torsions and infarctions [19].

The most effective treatment of an omental abscess is its removal within the limits of healthy tissues $[5,9,13]$. The other surgical methods described in the literature (simple drainage with packing and draining of an abscess cavity, drainage combined with marsupialization of the cavity $[7,10,13])$ should be used in special situations only, for example, in a combination of omental abscess with severe perivisceritis in which omental mobilization and resection are dangerous due to the potential for bowel loop injury. The omental resection is considered as optimal surgery for the omental abscess until now $[18,20]$. We believe, only in primary omental abscess a less-invasive intervention (the laparoscopic drainage [21] or the transparietal drainage under US or CT guidance) is justified. In our case, the laparoscopic surgery was much more risky than the open surgery in terms of possible bowel injury, and US-guided drainage was considered as non-reliable due to a high risk of the abscess recurrence. It was thought that an abscess was related to an infected ligature, and the simple abscess drainage without ligature removal could be unsuccessful. A similar situation can appear after the less-invasive drainage of the fecalithcontained abscess. The radical treatment in those cases is the open abscess drainage with fecalith(s) removal, otherwise the abscess recurrence is very likely [22].

The most important tool for the prevention of purulent omentitis is accurate omental resection. The omentum should be resected by small parts, avoiding the formation of large remnants, with ligation by thin threads [5]. The resection line should be drawn on a non-inflamed area $[5,9,10]$.

The presented case is an extremely rare case of a greater omental abscess that developed after appendectomy for perforated appendicitis in a young adult patient. However, given the anamnestic, clinical and instrumental data, we can consider this case as rather typical for intraabdominal abscesses. We hope this case will remind colleagues of the possibility of this postoperative complication.

\section{Acknowledgement}

The authors are grateful to Ekaterina G. Arap, State College of Publishing and Printing (Saint-Petersburg, Russian Federation), for her assistance in preparing the figure.

\section{Conflict of Interest}

None.

\section{Abbreviations}

US: ultrasound; CT: computed tomography

\section{References}

1. Matiashin IM, Baltaitis IV, Iaremchuk AI. Complications of Appendectomy. Kyiv, USSR: Zdorov'ya, 1974:1-223 (in Russian).

2. Chukhrienko DP, Bereznitskii IS. Intraabdominal Abscesses and Phlegmons. Kyiv, USSR: Zdorov'ya, 1977:1-136 (in Russian).

3. Nikol'skii VI, Sapozhkov AI. Abscesses of the Abdomen. Penza, Russia, 1994:1-201 (in Russian).

4. Cortesi N, Manenti A, Rossi A, Zanni C, Barberini G, Gibertini G. L'appendicite aigue et ses complications post-operatoires. A propos d'une serie de 8738 cas. J Chir (Paris). 1985;122(10):577-579 (in French). 
5. Odinak VM, Gridina GI. [Omentitis in children]. Khirurgiia (Mosk). 1987;(8):54-58.

6. Andreev GN, Alekseeva LA. [Acute omentitis]. Klin Khir. 1981;(1):38-40.

7. Stepanov EA, Kostomarova GA, Dronov AF, Smirnov AN, Blinnikov OI. [Inflammatory diseases of the greater omentum in children]. Vestn Khir Im I I Grek. 1986;136(4):86-89.

8. Iaremchuk A. [Inflammatory "tumors" of the greater omentum]. Khirurgiia (Mosk). 1984;(6):58-61.

9. Bairov GA, Golovanov Ia S. [Infiltrative subacute omentitis in children with acute appendicitis]. Vestn Khir Im I I Grek. 1988;140(1):116-120.

10. Beloblotskii VT, Kotel'nikov VG, Morozov EF, Grigor'eva VA. Inflammation of the greater omentum in children. Proc Crim Med Inst. 1978;76:93-95 (in Russian).

11. Golovanov Ia S. [Omentitis with abscess formation at a remote period after appendectomy in a child]. Khirurgiia (Mosk). 1989;(11):135-136.

12. Derzhavin VM, Ivanova MN, Gordeeva IP, Konovalov AK. Secondary acute omentites in children. Vopr Okhr Materin Det. 1986;31(8):29-32 (in Russian).

13. Elovoi MM. Acute diseases of greater omentum in children. Zdravookhr Belorus. 1985;(11):49-52 (in Russian).

14. Sitkovskii NB. [Chronic abdominal cavity abscesses in children after peritonitis due to acute appendicitis]. Klin
Khir. 1980;(6):6-9.

15. Iudin Ia B, Gabinskaia TA, Prokopenko Iu D, Val'tfogel IV, Zykina EV. [Secondary omentitis in children following appendectomy]. Klin Khir. 1989;(6):40-42.

16. Druianov BM, Gracheva NI, Deviatova NV. Inflammatory tumors of greater omentum. Khirurgiia (Mosk). 1974;(1):53-55 (in Russian).

17. Paliuga NI. [Abscess of the greater omentum after appendectomy]. Vestn Khir Im I I Grek. 1983;130(4):6970.

18. Hung CC, Chou CM, Chen HC. An omental abscess mimicking an intra-abdominal tumor. J Chin Med Assoc. 2012;75(3):136-138.

19. van Breda Vriesman AC, Lohle PN, Coerkamp EG, Puylaert JB. Infarction of omentum and epiploic appendage: diagnosis, epidemiology and natural history. Eur Radiol. 1999;9(9):1886-1892.

20. Lawson GA, 3rd, Castaldo ET, Miller RS. Primary omental abscess caused by Streptococcus constellatus: a case report. Surg Infect (Larchmt). 2010;11(3):339-341.

21. De Brabandere K, Vanpaemel G, Verheyen L. Spontaneous abscesses of the abdominal wall, omentum and abdominal cavity caused by group $\mathrm{G}$ streptococci: a case report. Acta Chir Belg. 2008;108(6):765-767.

22. Buckley O, Geoghegan T, Ridgeway P, Colhoun E, Snow A, Torreggiani WC. The usefulness of CT guided drainage of abscesses caused by retained appendicoliths. Eur J Radiol. 2006;60(1):80-83. 